\title{
A Preliminary Study on the New Generation Employees' Human Resource Management and Enterprise Sustained Competitive Advantage-From the Perspective of Resource-Based View
}

\author{
Jianwen Xiao \\ College of Business Administration, South China University of Technology, Guangzhou, China \\ Email: nicole81vip@163.com
}

How to cite this paper: Xiao, J.W. (2018) A Preliminary Study on the New Generation Employees' Human Resource Management and Enterprise Sustained Competitive Advantage-From the Perspective of Resource-Based View. American Journal of Industrial and Business Management, 8, 2364-2374.

https://doi.org/10.4236/ajibm.2018.812158

Received: November 19, 2018

Accepted: December 16, 2018

Published: December 19, 2018

Copyright $\odot 2018$ by author and Scientific Research Publishing Inc. This work is licensed under the Creative Commons Attribution International License (CC BY 4.0).

http://creativecommons.org/licenses/by/4.0/

\begin{abstract}
Recently, more and more people born in the 1980s and 1990s have stepped out of the ivory tower and entered the workplace. This group becomes more and more important in today's workplace; they bring new energy to the society. However, due to the differences in their growing background, some of their characteristics are increasingly recognized by managers. Complaining, job-hopping, emphasizing ego and lack of sense of responsibility are marked on this young group, which have created obstacles for managers to carry out their works. Aiming at such a young group, the limitation of the traditional system management has already appeared. In this paper, by analyzing on characteristics of new generation employees, author proposes a new idea of human resource management for the new generation employees, which is from the perspective of resource based view, not only to help enterprises to obtain sustainable competitive advantage, but also to provide a new direction for the management of new generation employees.
\end{abstract}

\section{Keywords}

Human Resource Management, Sustained Competitive Advantage, Resource-Based View, New Generation Employees

\section{Introduction}

With the deepening of economic development, nowadays, the main competition 
among enterprises has gradually turned into talent competition and talent-based management competition and technology competition. Therefore, human resources and their management are becoming more and more important in enterprise management. Nowadays, new generations of employees, such as the post-80s and post-90s, have begun to enter the workplace. These new generations of employees are different from the traditional employees because of their growth environment in the new era. On the one hand, they are full of personality, imagination and creativity. They are innovative avant-garde. Their ability to accept new thinking and new things is extremely high besides. On the contrary, they also have a low sense of organizational belonging, high turnover rate, and lack of teamwork awareness and so on. As the result, when a company is managing the new generation of employees, the traditional management system of the enterprise has obvious limitations. In the present, if a company can manage the new generation of employees scientifically and reasonably, it will inevitably greatly enhance its core competitiveness and become a winner among a lot of enterprises. Therefore, based on the characteristics of the new generation of employees and the shortcomings of the current traditional management system, this paper is innovatively proposing a new idea of the new generation of human resources management from the perspective of resource base; what's more, providing new directions for the management of a new generation of employees to help companies achieve sustainable competitive advantage.

\section{Resource-Based View}

The resource-based theory of enterprises published by Wernerfelt in 1984 means the birth of resource-based theory [1]. Wernerfelt put forward the "Resource-Based View" for the first time, emphasizing the importance of internal resources for enterprises to gain profits and maintain competitive advantage.

Jay Barney, the father of modern enterprise resource view, put forward the theory of resource-based view in his article "Enterprise Resources and Sustainable Competitive Advantage" in 1991. It means that there may be a kind of heterogeneous or difference between enterprises. When these heterogeneous or differences are valuable, scarce, hard to imitate and hard to replace, they enable enterprises to keep sustainable competitive advantage [2].

\section{Definition and Characteristics of the New Generation Employees}

\subsection{Definition of the New Generation Employees}

The new generation employees mainly refer to employees born after 1980 [3]. Since China began to implement the family planning policy in 1978, most of new generation is the only child in their family. Compared with those who have worked in the workplace for many years, they have more personalized tags. And, how to manage and retain the new generation employees has become a big challenge for enterprises managers. 


\subsection{Characteristics of the New Generation Employees}

1) New education and high emotional demand. The new generation employees accept the new education, which is more concerned on humanistic and emotional thinking than before, so they have higher expectations of emotion at work. The new generation of employees pursues a beautiful life; while salary is only a part of their pursuit, they pay more attention to the pursuit of happiness and the realization of self-worth. Through research and research on the life concept and work concept of graduates in 2014, the company which called Universum, found that more than $50 \%$ of the graduates in China in 2014 regard life quality as the same as career development [4]. So that, unlike the older generation employees who only pursue economic interests, they are not only hope to have an ideal salary level, but also have higher requirements on the human environment in workplace. In the survey, the author found that a large number of the new generation employees want to feel the warmth of the organizations during the process of work, as well as getting along well with colleagues and leaders.

2) Doing things in own way and have weak sense of discipline. In 1950s, the national family planning policy made the most of new generation employees is the only child in the family, which contributed their self-centered principles. They always insisted that they are right, and they don't want to follow the command of others, lacking of discipline awareness in the workplace [5].

3) Outstanding personality and lack of team concept. The changes of time background and family status make the new generation's personality more distinct. Because of the lack of the opportunity to get along with others and teamwork, they often lack the team concept in the process of work, and they are more difficult to cooperate with others to complete the task. In their eyes, the interests of the team are different from the benefit of themselves [6]. After analyzing the case of Foxconn's "12-hop", Lu Cui, Yang Peixing and Zhou Huan believe that one of the important characteristics of the new generation of employees is that they have stronger self-awareness but weaker teamwork awareness [7].

4) Enjoy wealth and honor, weak resistance to stress. Family members have been very fond of them and did everything for them since they were little babies, which lead to poor problem solving abilities, and their negative emotions can't be well resolved either. In the process of work, they can't face challenges and setbacks directly, these obstacles accumulate more and more, which lead to unhappy and even the psychological problem [8].

\section{The New Generation Employees for Enterprises to Obtain Sustainable Competitive Advantage}

As the fresh energy of the enterprise, the new generation employees is a new set of resources for enterprises to gain competitive advantages. According to the resource-based view, only when the resources are valuable, scarce, difficult to imitative and difficult to replace, they can obtain a lasting competitive advantage for the enterprise. Therefore, we will discuss whether the new generation em- 
ployees possess these four characteristics so that enterprises can obtain sustainable competitive advantage.

\subsection{The Value of the New Generation Employees}

As the freshest blood of the enterprises, the new generation employees are the latest and most advanced part of the enterprises' human resources. It brings new knowledge and skills to the development of enterprises and new ideas and views to the enterprises' culture. The new generation employees push the enterprises to keep up with the trend and to develop in a market-oriented manner. Therefore, we believe that the new generation employees are valuable to enterprises.

\subsection{The Scarcity of the New Generation Employees}

The knowledge and skill of each different individual is different. It is basically normal distributed in all human resources of the enterprise. Not all individuals have the same knowledge, skills and experience [9]. Moreover, the new generation employees are full of curiosity and tolerance for the outside world. They are willing to absorb new things and new cultures. In the dynamic process of interaction with the enterprises' culture and the working social environment, they are once again grinding and reshaping themselves, forming a different characteristic from other groups of other enterprises. Therefore, we believe that the new generation employees are scarce for the enterprises.

\subsection{The Hard Imitation of the New Generation Employees}

Because of their different growth environment, different educational experience and so on, new generation employees different characters, values, and different ways of treating people, which created the inability to imitate the characteristics of the new generation employees.

\subsection{The Hard Substitutability of the New Generation Employees}

The new generation employees, for an enterprise, is slightly less than the older generation in some experience based positions and jobs, but this does not mean that the new generation employees can be completely replaced for the business. The characteristics of the new generation employees have the brand of the times, which is the result of the development, and the social development and the economic change have shaped the internal and external characteristics of the new generation employees step by step. These characteristics are difficult to be replaced.

\section{The Current Problems of Human Resources Management of the New Generation Employees}

1) Cost-oriented construction of the environment, and the construction of enterprise culture lags behind

In the construction of hard working environment, enterprises choose to use 
cost-saving as the criterion and are not willing to spend manpower, material resources and financial resources to beautify the working environment. For the demands of the new generation of employees who want a more temperature and more emotional working environment, some managers even believe that this is a new generation employees out of thin air and in the emotional expression, not timely respond to them, even worse, they criticize these employees at the business conference. This kind of management behavior causes trauma to the psychology of the new generation employees and is not conducive to the smooth development of the management of these groups.

In the construction of soft work environment, the enterprise culture is going downhill because of the lack of attention of managers and the lack of support from employees. In the past, a company has fewer employees in one department, and everyone is familiar with each other. They work together to help each other. They will also meet and chat together after work. Everyone is a big family. Everyone shares a value and has a common Goal. Nowadays, the scale of enterprises is getting bigger and bigger, and there are more and more employees. It is difficult to gather all the employees. Therefore, some managers' enthusiasm for enterprise culture construction has gradually subsided. To a large extent, enterprise culture is only used for external propaganda, and there is no consensus among employees. Therefore, each department has its own affairs and there is very little communication between employees. Such enterprise culture and working atmosphere are contrary to the demands of the new generation employees seeking emotional support.

2) Focus on pursuing the interests of enterprises and lack of organizational construction

As a profitable organization, the interest of enterprises is the ultimate goal of their pursuit. As a result, the activities and projects that generate income for the company are welcomed by managers, while organizational construction that may increase costs for enterprises is put aside. What we are discussing here is mainly about the internal team building, system construction and other aspects besides enterprise culture. Nowadays, the competition between enterprises is aggravating, the managers are more only looking at the final data results and do not care about the process. Such result orientation directly leads to the neglect of the internal organization construction of the enterprise. The leaders will only point out the dissatisfaction with the results, but do not find the root of the dissatisfaction from the progress. All of this contributes reasons and direct reasons not only make the organizational performance stop, but also allow the new generation employees to have the resistance to the instructions of the superior, which hinders the development of the management. In addition, the neglect of the internal system construction of the enterprise also makes it easy for the new generation employees to be too self-centered, they lack of discipline consciousness and team consciousness, which makes it is difficult to cooperate with other members of the team to complete the task. Over time, they are isolated from the 
other members of the team. It is not conducive to good working atmosphere and the formation of interpersonal relationship network.

3) Training lag and blocked employees' realization of self-worth

The result orientation has also led managers to over-emphasize the spirit of hard work, focus only on the results of employee work, and pay no attention to the personal qualities and skills of employees, so that the training activities are not active. The industry's advanced technology and information are not timely taught to employees, what's more, The industry's advanced technology and information are not timely taught to employees, which let the employees' work efficiency is not improved, and they feel burnout at work. At the same time, because the training is not timely, the problems encountered by the employees in the work cannot be solved in time, the employees are suspicious of their ability to work, and they are dissatisfied with the positions they are engaged in. The new generation employees are expected to realize their own value in their work. Untimely training makes them unable to demonstrate their abilities well at work, and even question their ability to work, so unhealthy psychology will seriously hinder their future career development [10].

4) Insufficient attention to employee growth and lack of reasonable career planning and guidance

Under the command of the banner of profit-seeking, the work of the human resource management workers of the enterprise is largely the content of performance appraisal, punch card attendance and other employees' salary rewards. It is not timely to concern and understand the difficulties and problems faced by the employees. Due to their more extroverted personality and more explicit personality characteristics, the new generation employees may encounter more problems than the older generation employees in interpersonal and work processes, and their ability to deal with problems is weak, therefore, the demand for help and guidance from others is more urgent. But the managers of the enterprise and the staff of the human resources department do not pay attention to the characteristics and needs of the new generation employees in time, which leads to the psychological problems of the new generation employees.

In the career planning of the employees, the managers and human resources staff have no timely response to the different needs of the new generation employees at each stage. They did not provide timely guidance and suggestions for many multiple choice questions on the career path, allowing employees to grow step by step, the new generation employees are full of confusion about their career planning because of less guidance of the predecessors and the concern of the managers [11].

\section{New Ideas for Human Resources Management of New Generation Employees}

On the basis of the characteristics of the new generation employees and the problems existing in the management of human resources of the new generation 
employees, the author tries to give some new ideas for the management of human resources of the new generation employees from the environmental, organizational and psychological levels.

\subsection{Environmental Level}

\subsubsection{Working Environment}

As a place where employees work every day, the importance of the working environment within the company to employees cannot be ignored. From the placement of the decorations to the layout of the functional partitions, differences in these working environments may affect the work mood and work efficiency of the employees. Due to the good growth environment of the new generation, the new generation employees often have higher requirements for the working environment. They believe that a good working environment can make them feel happy at work, and stimulate their enthusiasm for work. On the contrary, an unsatisfactory working environment will make them feel dissatisfied with their work or organization, which leads to lack of positive motivation in their work.

Therefore, managers should not only pay attention to the performance of the new generation employees in their daily management, but also pay attention to the suggestions or dissatisfaction of the employees on the construction of the work environment. In terms of work environment construction, in addition to cost-oriented, it is necessary to meet the demands and needs of the employees as the starting point and the foothold. Moreover, the new generation employees can be involved in the design of the work environment, allowing them to put forward some suggestions for improvement, or allow them to decorate and arrange in their personal workspace according to their own preferences, so that they can find a sense of participation and belonging in their work.

\subsubsection{The Enterprise Culture}

One of the purposes of building enterprise culture is to transform traditional, passive and formalized management into cultural management. The new generation employees have their own way of doing things, and it is not uncommon to ignore the rules and regulations of the enterprise system. Under such circumstances, it is more effective to internalize the enterprise system into the values and codes of the new generation employees. Through the training activities of enterprise culture, the basic concepts, values, missions and visions of the enterprise will be conveyed to the new generation employees, so that they can standardize their behaviors on the basis of learning and feeling the foundation of the enterprise culture, and find a sense of belonging, which is the most effective management method for the new generation employees.

Managers should include humanistic care into building enterprise culture. As a spiritual category of enterprise culture, managers should work hard on humanistic care. Especially for the relatively emotional group of new generation employees, humanistic care is essential. Humanistic care is a kind of management 
style based on emotions [12]. Emotional as a link to unite all employees and create a harmonious big family atmosphere within the company, everyone has mutual understanding, mutual communication and mutual support. Human resources workers and managers should respect for the employee's status as a master, to meet the real needs of employees. When employees and their family members need help in an emergency, or have difficulties such as unexpected incidents in their daily family life, they should take effective measures to help them.

\subsection{Organizational Level}

\subsubsection{Management System}

Herzberg's two factor theory points out that there are two kinds of factors, Incentive factors and Health care factors [13]; the enterprise management system belongs to the latter. If the management system cannot serve the enterprise management well, it will cause the employees to produce negative emotions. Therefore, the timely improvement and update of the management system is a problem that every manager needs to pay attention.

The manager needs to realize that the management system is formulated and changed according to the actual situation of the enterprise. It is not an empty institutional framework, and it can't completely copy the management system of other enterprises. As more and more new generation employees enter the workplace, managers should update the existing management system in time according to the actual needs of the new generation employees. For new generation employees want a family emotional atmosphere, managers can organize weekly or monthly conferences from the perspective of the management system, or keep every holiday greetings, through such discussion forums or activities to reduce the distance between members of the enterprise, as well as enhance the affection between team members. A harmonious and warm organization will make the new generation employees more satisfied with their work and more energetic in their work.

\subsubsection{Organization Structure}

The new generation employees tend to emphasize themselves and are reluctant to obey their superiors. The traditional tedious and explicit instruction chain is not suitable for the enterprises and organizations of many new generation employees. On the contrary, the simple, flat organizational structure is more applicable to them. Flattening organization structure can be applied to a team or organization across different functions and levels. The flow of information between the team and organization is free and rapid. In addition, the level of centralization of a flat organization is low. This series of characteristics are exactly the new generation employees for equal rights, equal communication, concise and effective demands.

After the implementation of organizational flattening, the management level of enterprises is reduced, followed by the increase of the management range and 
the increase of the management difficulty. Therefore, the managers need to consider and deal with the degree of decentralization of the decision-making power, the management ability of the middle and lower level managers after the shift of power and the quality of the grass-roots employees, which are the three problems. In view of the degree of decentralization of decision-making power, managers need to redraw the power boundary, think about which power should be retained and which powers should be delegated. For the management ability of middle and lower level managers, senior managers should conduct a considerable and effective examination of them before delegating power, or arrange them to participate in training to improve their management ability. For the staff quality problem, because the flat organization structure rely more on staff with conscious dynamic role of the individual, managers should look at the employee's work practice, assessment and evaluation before deciding to implement flat organization structure, so as to ensure that employees can still do their job after organizational flattening.

\subsection{The Psychological Level}

\subsubsection{Establish Employee Confidence through Training}

The new generation employees are superior to their dignity and are weak in compression. Therefore, it is difficult for them to analyze and solve the problems in their work. In the face of the problems, they often choose to escape. In the long run, they lose confidence in themselves and are afraid of doing things. This will directly affect the efficiency of the work and the completion of the results.

In view of the lack of independent analysis and problem solving ability of the new generation employees, enterprises should organize some training activities appropriately. The scope of training should include both professional skills training and quality development training, which will improve the ability of business and improve the quality of employees as the purpose of training, and help the staff to build self-confidence. Training needs should be investigated from the management level, organizational performance level and employee level. The planning and arrangement of training should take into account the flexibility of staff and organizational working hours and the synchronization of job contents and training contents. In the way of training and implementing the method, there should be a specific selection, from the classroom teaching to the outdoor activities, from the case analysis to the hands-on practice. In view of the new requirements and new characteristics of the new generation employees, try to arrange some new training methods, so as to achieve twice the result with half the effort. In the evaluation of the training effect, it should be objective and fair, and should be combined with the performance assessment, appropriate and reasonable use of some incentives and policies to guide and stimulate the enthusiasm of the new generation employees to participate in training and the enthusiasm of the completion of the training task. 


\subsubsection{Engage in Timely Communication and Guidance to the Growth of Employees}

Compared with the older generation, the new generation employees lack the work experience and social experience. They often encounter problems in their work or are confused about the status quo. They need the proper intervention and help and guidance of the old employees of the enterprise. In view of the needs of the new generation employees, enterprise managers should pay close attention to and timely implement the communication guidance between the old staff and the new generation employees. In the previous article, we have discussed how to pay attention to and help the growth of the new generation employees in the system of staff symposium. Here we mainly emphasize an informal humanistic care for the new generation employees. In the enterprise, here is a kind of organizational atmosphere is formed to help the new generation of employees. For the confusion in their work and life, the other employees can help them independently. In view of some technical problems, the old employees can also be timely to teach their operation skills. In career planning, the staff of human resources should help them analyze their work ability, work prospects, learning orientation and promotion space. Through this targeted analysis and help, we can solve the problem that the new generation employees do not know how to learn and what to do next. Thus, the new generation employees will combine their development goals with the development prospects of the enterprises, and promote the performance of the new generation employees while promoting their work and learning enthusiasm.

\section{Conclusion}

From the perspective of resource-based view, the new generation employees are valuable, scarce, difficult to imitate, and irreplaceable, which can bring sustainable competitive advantage to the enterprises. As a new generation of energy in today's society and enterprises, the new generation employees should not be underestimated. Human resource management should be targeted to the new generation employees, especially for their emotional appeals, which should attract the attention of business managers and human resources workers, and pay attention to the growth of new generation employees from the environmental, organizational and psychological levels, concern the growth of the new generation employees demand, pay attention to humanistic care, and provide a temperature environment and atmosphere for the growth of new generation employees.

\section{Conflicts of Interest}

The author declares no conflicts of interest regarding the publication of this paper.

\section{References}

[1] Wernerfelt, B. (1984) The Resource-Based Theory of the Firm. Strategic Management Journal, 5, 171-180. https://doi.org/10.1002/smj.4250050207 
[2] Barney, J.B. (1991) Firm Resources and Sustainable Competitive Advantage. Journal of Management, 17, 99-120. https://doi.org/10.1177/014920639101700108

[3] Wang, S. (2018) New Generation Employee Management Problems and Countermeasure Analysis. Hebei Enterprises, 19-20.

[4] Trish, B. (2014) Encouragement. Translated by Lin Zhixun, Machinery Industry Press, Beijing, 141.

[5] Zhang, Q. and Tian, Y. (2018) Research on the Management of New Generation Employees-Taking SF Company as an Example. Modern Business, No. 26, 65-66.

[6] Xia, S.Y. (2015) Characteristics and Management Suggestions of New Generation Employees, Business, No. 6, 44-44+30.

[7] Zhang, G.L. and Zhou, J.F. (2015) A Review of the Definition and Characteristics of the New Generation of Employees. Journal of Wuhan University of Science and Technology (Social Science Edition), 17, 449-454.

[8] Ye, L.Q. (2018) Management Strategy of New Generation Employees after 90s. Technology Wind, No. 23, 248-249.

[9] Xie, H.Y. and Dai, L.T. (2012) On the Sustainable Competitive Advantage of Enterprises from the Perspective of Enterprise Human Resources Development-Based on the Perspective of Resource Basis. China Business \& Trade, No. 29, 100-101.

[10] Li, W., Liu, Y. and Liu, N. (2016) Research on Human Resource Management Problems and Countermeasures for the New Generation of Employees. Technology and Economy Guide, No. 20, 208.

[11] Xiao, J.M. and Zhang, H.S. (2013) Research on the Conflict of Human Resources Management by New Generation Employees. Science and Technology Economic Market, No. 9, 90-92.

[12] Zhou, J. (2013) How to Advocate Humanistic Care in the Construction of Enterprise Culture. Guide to Business, No. 2, 168.

[13] Herzberg, F., Mosner, B. and Snyderman, B.B. (2016) Herzberg's Two-Factor Theory. Translated by Zhan Zhang, Revised Edition, Renmin University of China Press, Beijing. 